\title{
Areas de actividad doméstica en Pueblo Viejo de Tucute (Puna de Jujuy)
}

María Ester Albeck ${ }^{1}$

\section{RESUMEN}

La excavación y el análisis de los materiales arqueológicos del recinto 1 de Pueblo Viejo de Tucute, ubicado en la Puna de Jujuy, ha permitido definir diferentes áreas de actividad en el interior de la vivienda. La dispersión areal, asociación y estado de conservación de los materiales permiten proponer áreas preferenciales para el desarrollo de ciertas actividades domésticas como molienda, elaboración y consumo de comidas, almacenamiento y descanso.

\begin{abstract}
The excavation of house 1 in Pueblo Viejo de Tucute (Puna de Jujuy) and the further analysis of the archaeological finds show differents activity areas inside the dwelling. Preferential áreas for certain domestic activities like grinding, food elaboration and consumption, storage and resting places are proposed following the areal dispersion, association and conservation of the archaeological finds.
\end{abstract}

La cantidad y diversidad de elementos recuperados en la excavación del recinto (Rl) de Pueblo Viejo de Tucute han permitido realizar una serie de observaciones sobre los materiales y las actividades desarrolladas por sus antiguos ocupantes.

Un registro cuidadoso de los hallazgos en el campo y su posterior análisis en el laboratorio han brindado la posibilidad de definir áreas de actividad (Binford 1978; South 1979). En este caso particular nos referimos a las tareas domésticas llevadas a cabo en el interior de la vivienda arqueológica. Tanto el carácter excepcional del contexto como la dispersión areal de los diferentes elementos recuperados, su asociación, superposición, estado de conservación y relación presencia-ausencia han resultado claves en el análisis. Estos criterios han servido para intentar reconstruir algunos aspectos de la vida diaria de los antiguos habitantes del recinto 1 y la formación de la estratigrafía en el interior de la vivienda desde los inicios de la ocupación hasta el presente.

1 CONICET - Facultad de Humanidades y Ciencias Sociales, Universidad Nacional de Jujuy, San Salvador de Jujuy, ARGENTINA.
A partir del análisis del registro se proponen ciertas áreas preferenciales para el desarrollo de actividades domésticas como molienda, elaboración y consumo de comidas, talla lítica, fabricación cerámica y otras.

\section{El sitio}

Pueblo Viejo de Tucute (Tu-1) se encuentra en el área de influencia del poblado moderno de Casabindo (Depto. de Cochinoca) en el noroeste de la Provincia de Jujuy, sobre la falda oriental de la sierra de Casabindo $\left(23^{\circ} \mathrm{S} 66^{\circ} \mathrm{O}\right)$.

Pueblo Viejo de Tucute fue visitado por Uhle a fines del siglo pasado. Este sitio también es conocido en la literatura arqueológica como Pueblo Viejo de Casabindo (Boman 1908) y Sorcuyo (Casanova 1938). Entre los pobladores de la zona se lo nombra, además, como Antigal de Río Negro.

Si bien Sorcuyo es el término más difundido para nombrar este sitio, es un topónimo actualmente desconocido en la zona. Hemos preferido el de Tucute porque, además de ser el primer nombre con el cual se lo conoció, es el que se mantiene hoy en día para la quebrada que alberga el antiguo asentamiento.

Pueblo Viejo de Tucute se encuentra a 3700 m.snm sobre el arroyo de Tucute a $1.5 \mathrm{~km}$ de su confluencia con el río Negro, al suroeste del poblado actual de Casabindo. El sitio se ubica sobre ambas márgenes, ocupando una lomada baja, próxima al curso de agua y otra mucho más elevada. La parte baja del sitio se encuentra protegida entre elevados paredones rocosos, la parte alta del sitio se halla mucho más expuesta a las inclemencias del clima (heladas, vientos y tormentas eléctricas).

En Tu-1 se registraron dos ocupaciones con recintos de construcción bien diferenciados. El asentamiento más reciente con recintos de planta rectangular pertenece al Tardío-Desarrollos Regionales y se halla sobreimpuesto a otro asentamiento, que es el que nos interesa en esta oportunidad, con viviendas de planta circular que ubicaríamos tentativamente en el 
Formativo Superior y Período Medio. Estimamos que el sitio podría ubicarse temporalmente antes de 900 DC. Las evidencias en favor de esta ubicación cronológica serían: 1) la forma circular de las viviendas, 2) la presencia de piezas alfareras con modelados de llama, características del Formativo y del estilo cerámico La Isla, respectivamente y 3 ) fragmentos de alfarería pintada en negro y rojo, si bien en ínfima cantidad, 4) puntas de flecha de base escotada y 5) pucos con su interior negro pulido, abundantes en el momento Tardío de la región.

\section{Trabajos realizados}

En Tu-1 se han realizado sondeos exploratorios en dos viviendas circulares. El primer sondeo se efectuó en el recinto 0 , ubicado en la parte elevada del sitio, el segundo se practicó en la vivienda Rl de la lomada baja. Posteriormente se excavó este recinto en su totalidad. Las tareas de excavación se llevaron a cabo durante tres campañas en los años 1986, 1987 y 1988.

El recinto 1 se encontraba relativamente bien conservado, se identificaba claramente el vano de acceso y contaba, además, con una buena sedimentación en su interior. La antigua vivienda se ubica contra el borde del asentamiento, en el sector nororiental de la lomada baja. En las proximidades se encuentra otro recinto de iguales características pero en inferiores condiciones de conservación. Ambas construcciones se ubican sobre una pequeña terraza limitada por una pirca que corre contra el quiebre de pendiente hacia el arroyo.

El interior del recinto presentaba vegetación de arbustos y abundantes piedras, producto del derrumbe de las paredes. En superficie se encontró un fragmento de piedra de moler, escasísimo material cerámico y una piedra esculpida, de forma cónica, clavada cerca de la pared, en las inmediaciones de la entrada.

El recinto 1 tiene $5.11 \mathrm{~m}$ de diámetro norte-sur y $5.22 \mathrm{~m}$ de diámetro este-oeste, conformando una planta circular casi perfecta. El sondeo inicial de $1 \mathrm{x}$ $1 \mathrm{~m}$ se ubicó en la parte central del recinto, contra la intersección de los diámetros N-S y E-O. El sondeo inicial se denominó SO y fue efectuado con el propósito de identificar los niveles de sedimentación natural antes de proceder a la excavación del resto de la vivienda.
En el sondeo inicial se identificaron tres niveles de sedimentación denominados I, II y III desde el más superficial hasta el más profundo.

Nivel I: corresponde a un sedimento arenoso de tono beige claro que contiene pocos elementos culturales. Este estrato se habría acumulado con posterioridad al abandono de la vivienda.

Nivel II: comprende un sedimento de textura más firme y color oscuro por las partículas de carbón que incluye. Este nivel corresponde al tiempo en que el recinto era habitado y contiene abundantes elementos culturales, en particular fragmentos cerámicos y restos óseos.

Nivel III: es el más profundo y pertenece a la roca de base del cerro compuesto por pequeñas lajas con algo de sedimento más fino. Este nivel es totalmente estéril.

Nivel Ib: contra el perímetro del recinto (no en el sondeo $\mathrm{SO}$ ) se registró la presencia de un nivel estratigráfico de naturaleza diferente a los tres descritos con anterioridad, que ocupa las áreas adyacentes a la pared donde alcanza su máxima potencia. El espesor del sedimento va disminuyendo paulatinamente hacia el interior del recinto donde es inexistente. En este nivel, que denominamos $\mathrm{Ib}$, aparecen incluidas numerosas piedras de derrumbe de las paredes y fragmentos de cerámica, en general de gran tamaño. Este nivel corresponde a la primera etapa de desocupación y abandono de la vivienda, en la cual se desploma el techo y comienza el derrumbe de las paredes, fracturando los objetos que se encontraban en el interior de la misma.

A partir del sondeo inicial se excavó el recinto por cuadrantes y siguiendo los ejes N-S y E-O. En la primera campaña se excavaron los cuadrantes suroeste y noroeste. En la segunda campaña se excavó el cuadrante sureste y en la última campaña el cuadrante noreste. Los sectores delimitados, de 1 $\mathrm{x} 1 \mathrm{~m}$ fueron numerados en forma correlativa a partir del centro, siguiendo ejes paralelos N-S y según el orden de excavación de los cuadrantes, en total suman 31. En las áreas centrales del recinto son de forma cuadrada pero contra el perímetro adquieren formas irregulares (Figura 1). 

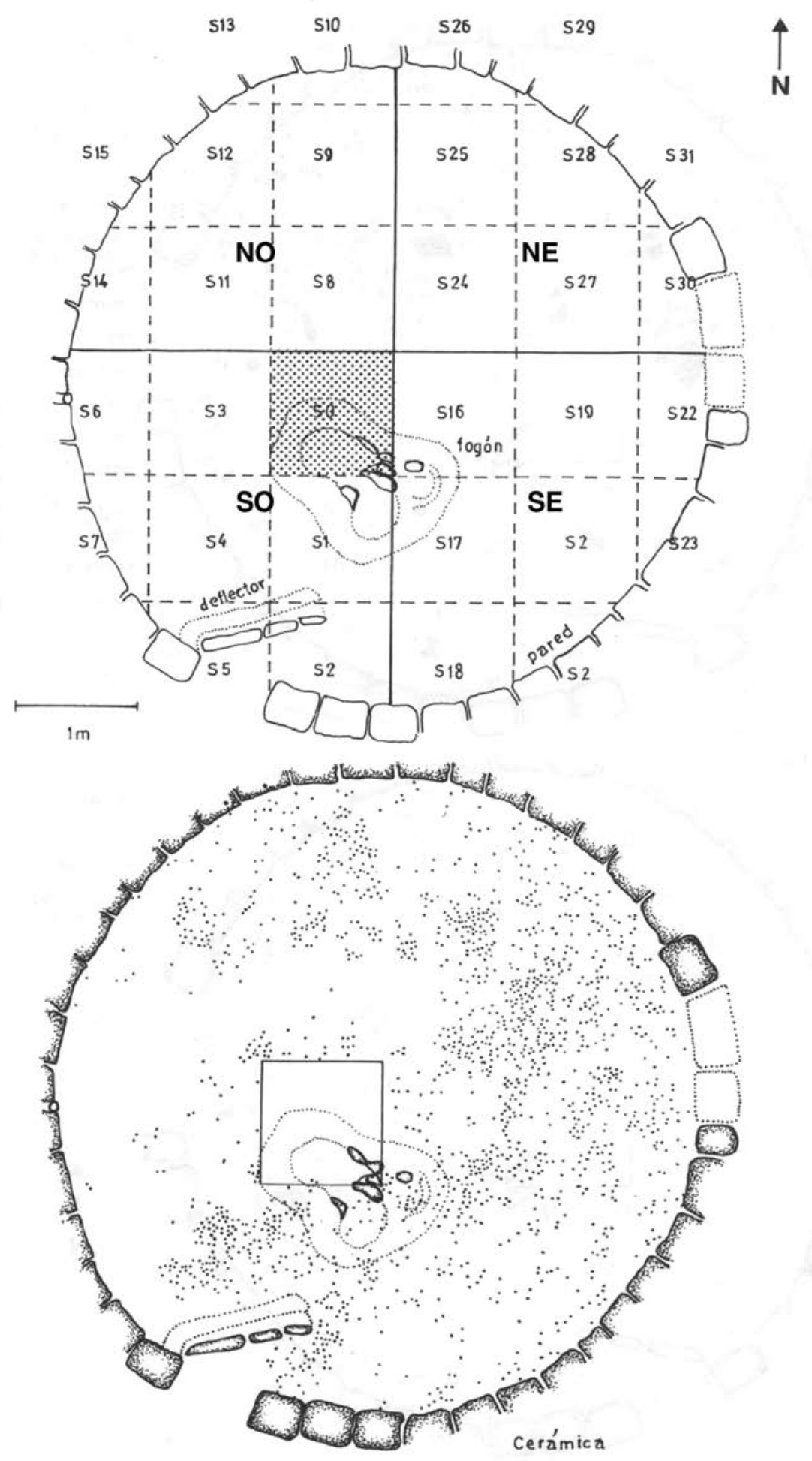

Figura 1. Sectorización del recinto 1 (R1) y dispersión de los fragmentos cerámicos en el interior de la vivienda. 
Para la excavación se procedió de la siguiente manera: se levantaron inicialmente las piedras de derrumbe sueltas en la superficie del cuadrante y se levantó todo el Nivel I tomando como referencia el sector oeste. El sedimento removido fue harneado con malla de $1 \mathrm{~cm}$. En este nivel se recuperaron escasísimos restos culturales, en general fragmentos cerámicos de tamaño pequeño.

El Nivel Ib y el Nivel II se excavaron con sumo cuidado. Para cada sector se levantó un plano con la distribución de los elementos culturales. Se asignaron números a los diferentes hallazgos y se registró la profundidad; cuando la acumulación de hallazgos era muy densa o cuando existía superposición de materiales fue necesario levantar más de un plano. El número de plantas por sector fue variable, desde un solo plano hasta nueve (S. 27). Se prosiguió hasta alcanzar el Nivel III estéril.

Se recuperó todo el material cerámico, lítico (las piezas grandes fueron fotografiadas y dejadas en el sitio en las proximidades del recinto excavado), óseo, vegetal, carbón, etc. El material cerámico y lítico fue numerado en su totalidad, excepto los fragmentos y piezas pequeñas que se rescataron de los harneros. El material óseo, en cambio, fue numerado en planta tan sólo cuando se consideró que era factible identificar la pieza esqueletal en laboratorio. Cuando ocurría así, por ejemplo en el caso de los huesos muy fragmentados y en mal estado de conservación, se registró el hallazgo en planta con la profundidad correspondiente, pero no se le asignó número identificatorio. Los niveles fértiles fueron mucho más potentes en el área oriental del recinto, en particular en el cuadrante noreste. En esta parte la superficie original de la lomada, donde se ubicó la vivienda, tenía una leve pendiente hacia abajo.

Al iniciarse la segunda campaña se constató que parte del sedimento del recinto había sido removido por huaqueros. El cuadrante huaqueado, el noreste, recién fue excavado en la tercera y última campaña. Se pudo comprobar que el daño había sido menos significativo que lo que se había temido. El saqueo afectaba los niveles superficiales de los sectores S. 27, S. 28 y S. 31. Se había removido principalmente el sedimento de relleno (niveles I y Ib) y prácticamente no se habían dañado los niveles de ocupación.

\section{Hallazgos}

Del recinto 1 excavado en su totalidad se recuperó abundante material, en particular fragmentos cerámicos, material óseo y restos de vegetales carbonizados.

Material cerámico: El techo del nivel de ocupación, vale decir, el último piso transitado antes del abandono de la vivienda, se identificó claramente por la gran concentración de material cerámico, especialmente fragmentos grandes que prácticamente tapizaban el suelo en algunos sectores excavados. Muchos fragmentos corresponden a piezas completas, rotas in situ. Estos se encuentran apoyados o parcialmente clavados sobre el Nivel II y contenidos en el Nivel Ib y ocasionalmente en el Nivel I. Los fragmentos contenidos en el Nivel II eran en general más escasos y de menor tamaño. La gran mayoría corresponde a cerámica ordinaria de buena factura. Se recuperaron fragmentos de piezas con pintura roja y pucos con el interior negro pulido. Se rescataron escasísimos fragmentos decorados, pintados en negro y rojo.

En cuanto a la forma y tamaño de las vasijas se podrían definir dos grupos formales, escudillas o pucos y vasijas restringidas con cuello, que numéricamente son los más significativos. Las vasijas restringidas con cuello se dan en los tres grupos por tamaño: pequeñas, medianas y grandes, siendo más numerosas las de gran tamaño. Las escudillas comprenderían dos grupos por tamaño, pequeñas y medianas, predominando las pequeñas. A estos dos grupos formales habría que agregar otros, poco representados, como vasijas con modelados zoomorfos (llama).

Material lítico: Los artefactos líticos fueron menos abundantes que los demás elementos considerados. Lo más notorio fue la gran cantidad de piedras pulidas vinculadas a la molienda (manos, molinos planos y morteros) que aparecieron enteras o fragmentadas. Se rescataron numerosas lascas, en general de obsidiana, tres puntas irregulares de base escotada y una raedera, también de obsidiana. Otros artefactos líticos dignos de destacar son pequeños pulidores de piedra elaborados sobre diferentes tipos de roca. El registro de artefactos líticos se completa con dos percutores, un colgante o pendiente y dos torteras circulares, elaboradas sobre lajas delgadas y un fragmento de pala lítica.

Por último, destaca la presencia de abundantes concreciones de arcilla rojiza. Contra uno de los vanos de acceso se encontró un anillo de piedra, al parecer conformado naturalmente. 
Material óseo: La mayor parte corresponde a fragmentos no identificables. La inmensa mayoría de las piezas esqueletales identificadas pertenece al género Lama. Se constató, además, la presencia de Lagidium viscacia (roedor). Con referencia a la densidad de restos óseos, se debe destacar que en el último piso ocupado es muy escasa, mientras que en las partes más profundas del Nivel II aumenta considerablemente.

Inhumación de párvulo: En el área próxima a la entrada se registró un conjunto de lajas ubicadas intencionalmente que cubrían una inhumación. Los restos óseos se hallaban depositados en un pequeño hoyo excavado en el piso de la vivienda. Estos restos pertenecen a un humano, nonato o neonato.

Restos vegetales: Fueron encontrados mayormente en las partes más bajas del nivel de ocupación (Nivel II), con frecuencia entre las lajitas que asomaban del nivel estéril (Nivel III). El número de especímenes rescatados supera 100, y corresponden a granos de maíz y tubérculos de papa carbonizados. Se rescataron, además, restos de tres semillas carbonizadas no identificadas. Vinculados a los restos vegetales se registraron concreciones, también carbonizadas, de una sustancia de apariencia resinosa con abundantes burbujas de aire. Los análisis determinaron que se trata de una sustancia orgánica.

Carbón: Los hallazgos de carbón fueron abundantes, con una máxima concentración en las áreas cercanas al fogón. En general se trataba de espículas y trozos pequeños pero se recuperaron algunos de gran tamaño. En ciertas oportunidades se pudo identificar el tipo de madera carbonizada: cardón (Trichocereus sp.) y queñua (Polilepys tomentella).

Otros: Corresponden a un fragmento de soga de fibra indeterminada y a fragmentos de soga carbonizados, aparentemente fabricadas con hojas de gramíneas retorcidas.

\section{Distribución espacial}

Para elaborar los planos se ha trabajado con los dibujos de planta de cada sector excavado que suman 87. Estos planos sintetizan la dispersión de cada tipo de material rescatado (cerámica, lítico, hueso, etc.) dentro del recinto 1 . Del análisis de estos planos surgen las ideas sobre áreas de actividad (Binford 1978; South 1979) expuestas a continuación.

Según se desprende de los gráficos (Figuras 3 a 5) es notable la distribución diferencial que muestran algunos elementos. Si exceptuamos la cerámica (Figura 3) con una frecuencia regular en gran parte del recinto, los demás elementos se distribuyen de manera bastante localizada. Como consideramos que los elementos rescatados corresponden a una única ocupación, se ubicaron en el plano sin indicación de profundidad.

El total de puntos ubicados en los gráficos, a los cuales corresponde un número de registro, asciende a 1573 . De éstos, 226 se ubican en el cuadrante noroeste, 257 en el cuadrante suroeste, 519 en el sureste y 571 en el noreste. Los cuadrantes con menos hallazgos son los dos primeros, el sector suroeste, en particular, presentaba áreas casi sin material. El cuadrante noroeste fue el que presentaba la menor densidad de hallazgos y gran parte de los mismos eran restos vegetales carbonizados.

En la Figura 1 consta la dispersión de los hallazgos de fragmentos cerámicos en el interior de la vivienda. Las grandes concentraciones de puntos en el gráfico corresponden a piezas que quedaron enteras cuando la vivienda fue abandonada, posteriormente fueron rotas al producirse el colapso de la misma. Los fragmentos contenidos en el Nivel II presentan una dispersión más uniforme. En el Nivel Ib las mayores concentraciones se registraron en las áreas centrales del recinto (S. 9, S. 17, S. 19, S. 25 y S. 27) y en las proximidades del fogón (S. 1 y S. 4). En las áreas cercanas a las paredes casi no aparecieron fragmentos de piezas completas rotas in situ. En los sectores S. 22, S. 24 y S. 27 se recuperaron las bases de tres vasijas pequeñas. Los fragmentos pertenecientes al Nivel II corresponden a piezas fragmentadas mientras la vivienda aún era habitada. Estos fragmentos se concentran en los cuadrantes sureste y noreste, en particular en este último, donde el estrato de ocupación era más potente por el desnivel existente en la superficie original.

En la Figura 2 se registra la dispersión de los elementos líticos. Estos son los que se pueden relacionar a la mayor diversidad de actividades, desde tareas relacionadas a la elaboración de alimentos hasta labores agrícolas y fabricación de cerámica. $\mathrm{La}$ mayor concentración de restos la observamos en los 
sectores S. 3, S. 11, S. 24 y S. 27. Los fragmentos de manos de moler y conas se encontraron en las áreas centrales del recinto en relación al fogón. Las lascas de obsidiana se hallaron en los cuadrantes sureste y noreste, donde también se rescataron las puntas de flechas y la raedera. Los numerosos pulidores pequeños de piedra y los núcleos de arcilla rojiza provienen exclusivamente del cuadrante noreste, y las dos torteras y el colgante del cuadrante suroeste.

La Figura 2 registra la dispersión del material óseo, que presenta una distribución bastante curiosa en el interior de la habitación. Las mayores concentraciones se dan en las áreas adyacentes a la pared de los cuadrantes noreste y sureste. Resulta destacable la baja incidencia de este tipo de material en el cuadrante suroeste, especialmente en los sectores S. 3, S. 4, S. 5, S. 6 y S. 7. La acumulación de huesos en el sector S. 18 corresponde a la inhumación.

En la Figura 3 se presenta la dispersión de los restos vegetales, que se restringen casi exclusivamente al cuadrante noroeste (S. 8, S. 11 y S. 12). Aquí se recuperaron casi todos los restos de tubérculos de papas y semillas de maíz carbonizados, aunque también aparecen en otros cuadrantes. Los restos de sogas quemadas se encuentran en general, en los mismos cuadrantes que los restos de cultivos. Las tres semillas carbonizadas, aún no identificadas, se recuperaron en las proximidades de la inhumación, en el sector S.18.

La Figura 3 grafica la distribución de los fragmentos de carbón y la sustancia resinosa con burbujas. El carbón presenta una dispersión regular en toda la superficie excavada, en especial las partículas pequeñas que se hallan incluidas en el Nivel II. Los grandes trozos de carbón tienden a concentrarse en las áreas cercanas al fogón y son menos frecuentes contra las paredes del recinto. Los restos de la sustancia resinosa están mayormente en el cuadrante noroeste.

\section{Formación de la estratigrafía del recinto l}

Antes de tratar las áreas de actividad definida para este recinto haremos unos comentarios sobre la formación de su estratigrafía (Schiffer 1983). Las ideas volcadas aquí no son, de manera alguna, definitivas; consideramos que podrían estar sujetas a modificaciones cuando hayamos concluido el trabajo de laboratorio. La cantidad de fragmentos cerámicos que aparecen en el último piso de ocupación, pertenecientes en general a unas pocas piezas que remontan (grandes, medianas y chicas), nos indicarían que éstas se encontraban enteras en el interior de la vivienda en el momento en que ésta fue abandonada. Posteriormente, el derrumbe del techo y de las paredes ocasionó la rotura de las vasijas. Un hecho que refuerza esta opinión es la imposibilidad de desplazarse en un ambiente con tanta concentración de tiestos a nivel del piso, sin causar disturbios en su distribución.

El derrumbe de la vivienda sería coincidente con el momento en el cual se depositó el sedimento amarillo (Nivel Ib). Los fragmentos de las piezas que remontan aparecen sobre el Nivel II, algunas veces parcialmente clavados en este nivel, pero incluidos en el sedimento amarillo. Este tipo de sedimento se podría vincular, tal vez, con un episodio climático más seco. El sedimento es arenoso y el modo en que se encontraba depositado (ausente en el centro del recinto y en la zona de acceso y con un máximo de espesor contra el perímetro del mismo) reforzaría la idea de una depositación eólica. Este episodio debió tener una duración significativa, a juzgar por la potencia de los sedimentos contra las paredes y la inclusión de rocas de derrumbe dentro del mismo. Con posterioridad a este episodio se depositó el sedimento beige del Nivel I, que es el que continúa hasta el presente. La mayor parte de las rocas de derrumbe se halla incluida o sobre este sedimento.

La naturaleza de los fragmentos óseos y cerámicos incluidos en el Nivel II nos indicarían que los habitantes de recinto 1 limpiaban la vivienda depositando la basura en otro lugar. En el Nivel II, los fragmentos son de menor tamaño y pertenecen a una gran cantidad de piezas, cuyo número exacto no se ha establecido todavía, y que en general no remontan (Schiffer 1983). La gran cantidad de restos óseos fracturados serían indicadores del tránsito en el interior de la vivienda. Los huesos enteros, en general, se encuentran en las áreas cercanas a las paredes, donde el tránsito es mínimo. Estas áreas tienen mayores posibilidades de conservar elementos de depositación primaria (Wilk y Schiffer 1979).

Tanto el tránsito en el interior de la vivienda como la limpieza regular serían aspectos negativos para intentar definir áreas de actividad doméstica en el recinto 1 . Sin embargo, la dispersión de algunos 


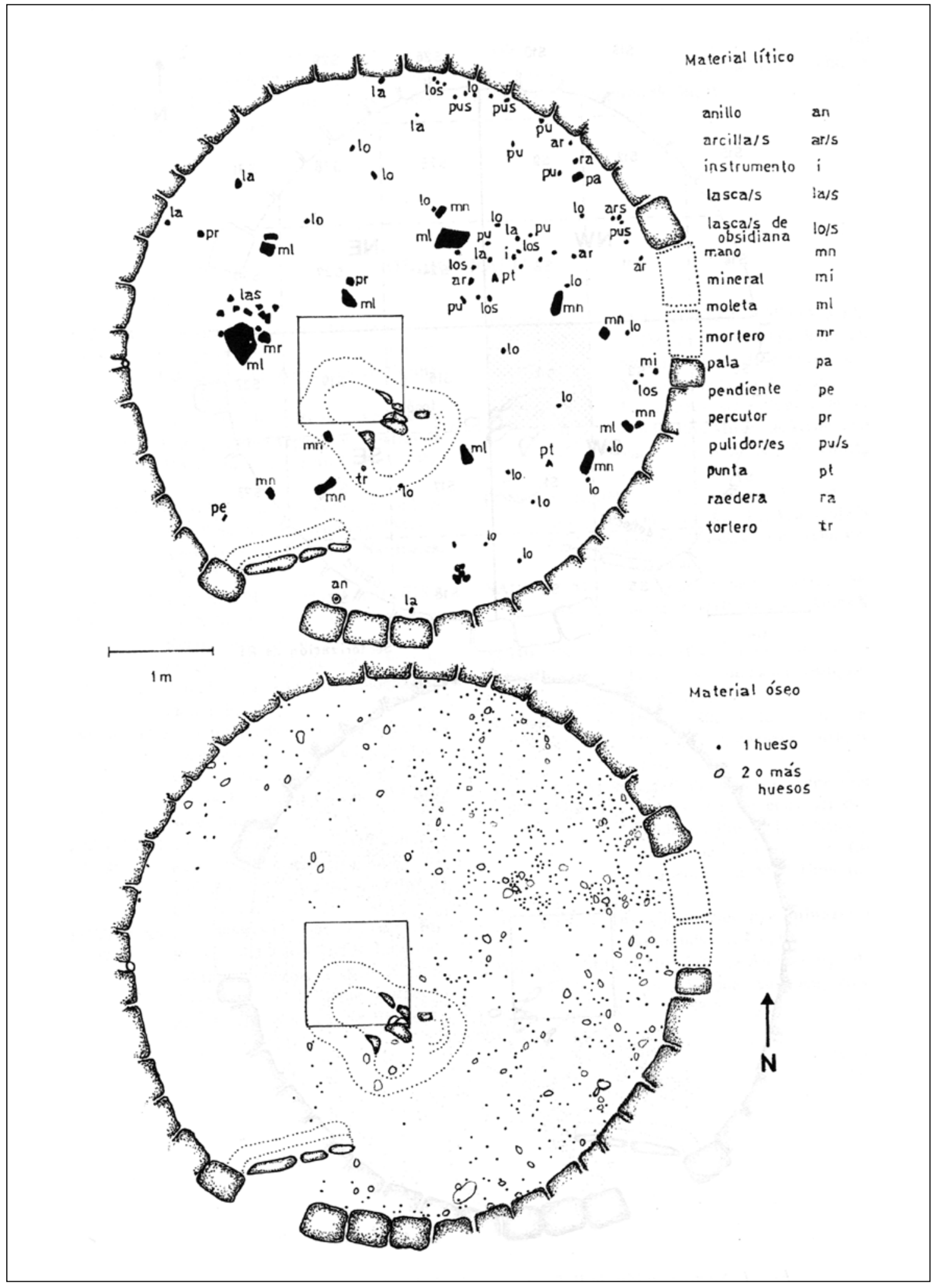

Figura 2. Distribución del material lítico y material óseo en el interior del recinto 1. 

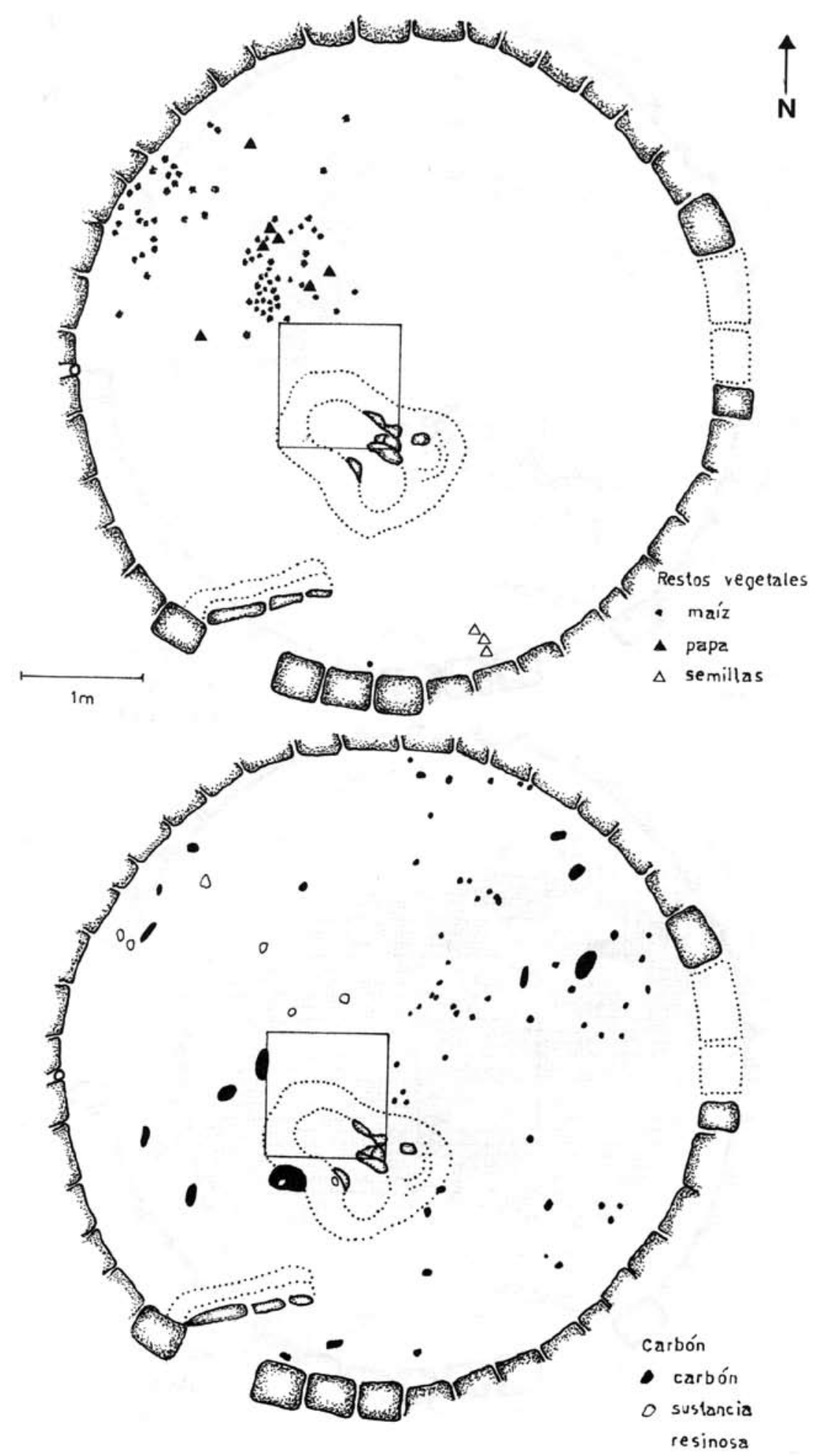

Figura 3. Distribución de restos vegetales y carbón en el recinto 1. 
elementos es tan particular que no creemos que se puedan referir a hechos fortuitos, sino que responden a la utilización del espacio interno de la habitación para diversas tareas y que éstas se realizaban en áreas preferenciales.

\section{Areas de actividad doméstica en el recinto l}

La técnica de registro empleada en la excavación del recinto 1 nos ha permitido inferir algunas ideas preliminares sobre la utilización diferencial de algunas áreas del interior de la vivienda arqueológica.

Tomando como base la planta de la habitación y los gráficos que discriminan los elementos según el tipo de actividad al cual se encuentran vinculados (Figuras 4 y 5) se pueden establecer áreas funcionalmente diferenciales. Hasta el momento se han logrado determinar las siguientes áreas funcionales: fogón, molienda, elaboración y consumo de comidas, almacenamiento, talla lítica, hilado, elaboración de cerámica, descanso e inhumación.

Acceso: El acceso al recinto 1 se hacía por una abertura ubicada hacia el sur, frente al vano de la puerta se encontraba un deflector de aire, colocado en forma oblicua, orientado sobre un eje SO-NE. La puerta de entrada demarcaba con el deflector un corto pasillo de tránsito obligatorio para acceder al interior. Esta era un área que, en general, se encontraba libre de hallazgos, por tratarse de un área de circulación. Unos pocos fragmentos óseos y cerámicos constituyen la excepción.

Fogón: Limitado por piedras de canto, se ubica en una posición levemente excéntrica en el recinto circundado enteramente por concreciones de tierra quemada y parcialmente excavado en el piso. A un costado del fogón se constató la presencia de un pequeño reborde semicircular de arcilla cruda que probablemente haya servido para asentar las vasijas. El fogón, seguramente, se hallaba relacionado tanto con las actividades culinarias como con la calefacción de la vivienda en los días de frío y al atardecer.

Molienda: En esta actividad incluimos los molinos planos, manos, mortero y percutores. Si bien los fragmentos de manos aparecen en diversos sectores del recinto, las moletas o molinos planos, mortero y percutores se ubican en una posición central dentro de la vivienda, próximos al fogón y opuestos al acceso. Esta actividad se desarrolló principalmente en el cuadrante noroeste y en parte en el noreste. Los percutores los hemos vinculado a la molienda porque se ubican en un sector donde este tipo de tareas es casi exclusivo.

Elaboración de comidas: A pesar de que la molienda está íntimamente relacionada a la elaboración de las comidas, la hemos discriminado porque los vestigios referidos a ambos tipos de actividad no se superponen totalmente. El procesamiento de alimentos es notable en el cuadrante noroeste donde aparecieron los restos de vegetales carbonizados y la sustancia orgánica resinosa que hemos vinculado a las tareas culinarias. En la elaboración de las comidas también participan el fogón y probablemente algunas vasijas.

Consumo de comidas: Aunque en el Nivel Ib se recuperaron tan sólo dos pucos, uno pequeño y otro de tamaño mediano, la gran cantidad de fragmentos de pucos, particularmente de tamaño pequeño, rescatados del Nivel II, sugieren el consumo de comidas en el interior de la vivienda, aunque no se pueda establecer un área preferencial para esta actividad.

Almacenamiento: El hallazgo de grandes vasijas rotas in situ en diferentes partes de la vivienda posiblemente esté relacionado con el almacenamiento. Estas grandes piezas alfareras se ubican en tres partes de la habitación. En el cuadrante suroeste, entre el fogón y el deflector en el cuadrante noroeste y hacia el este sobre el eje que separa los cuadrantes noreste y sureste. Las grandes vasijas debieron servir para el almacenamiento, tanto de líquidos como de sólidos y dada la presencia de maíz, pudieron servir también para la elaboración de chicha. Un análisis más detallado de las formas, pastas y evidencias de uso nos podrían dar una visión más ajustada de la funcionalidad. Cercanas a este eje, también se recuperaron las bases completas de tres vasijas fracturadas que conformaban pequeñas escudillas. Estas piezas las hemos relacionado con el almacenamiento de cosas pequeñas, aunque en estos casos, dada la posición que ocupan, no las vincularíamos directamente con el almacenamiento de alimentos.

Inhumación: La inhumación de un niño recién nacido o nonato en un pequeño hoyo y tapado con una cubierta de lajas muy delgadas se ubica próxima a la pared y cercana a la zona de acceso a la vivienda. La única inhumación registrada en el interior de la vivienda plantea un interrogante. 

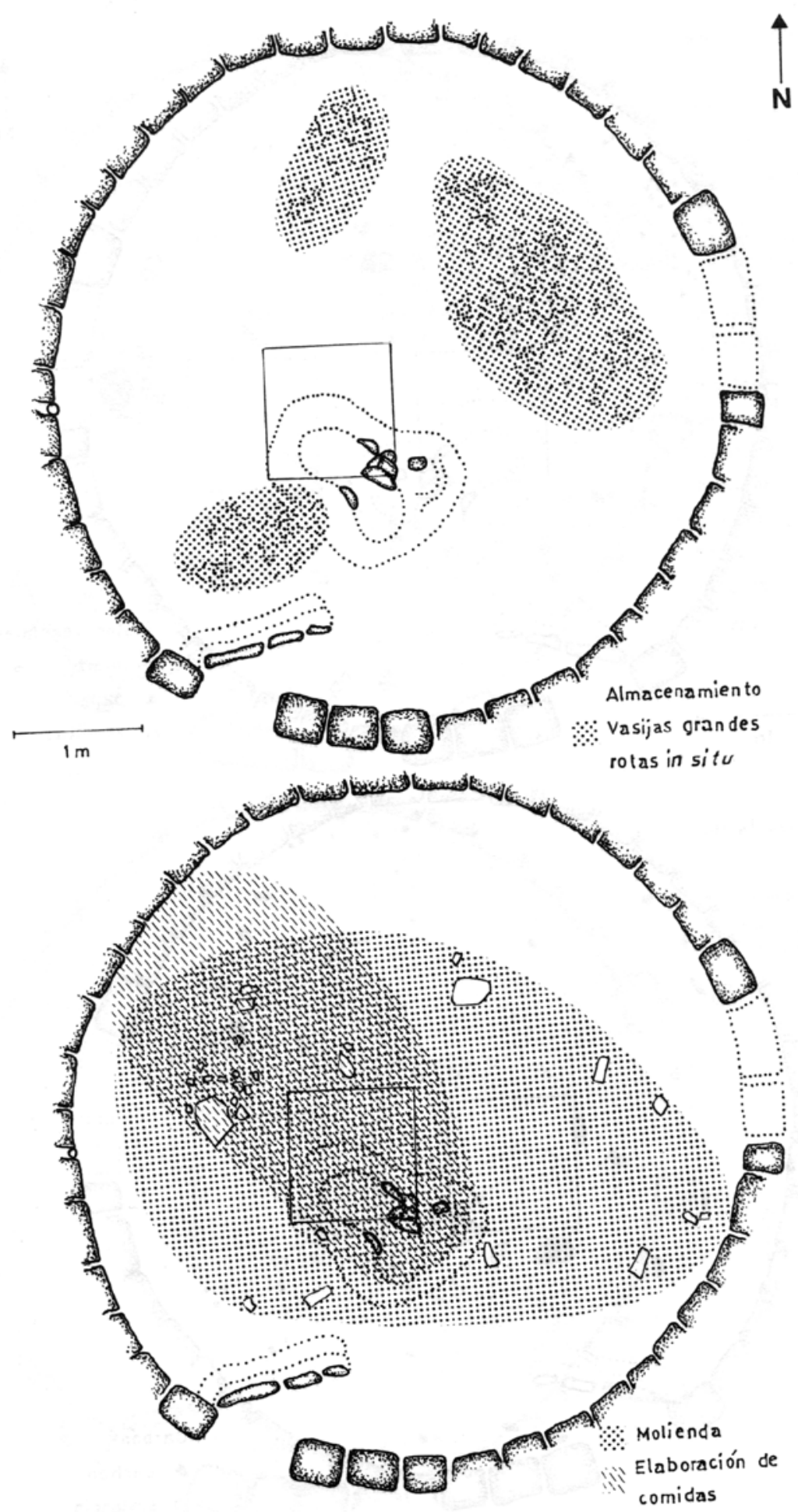

Figura 4. Areas de almacenamiento, molienda y elaboración de comidas en el interior del recinto 1. 

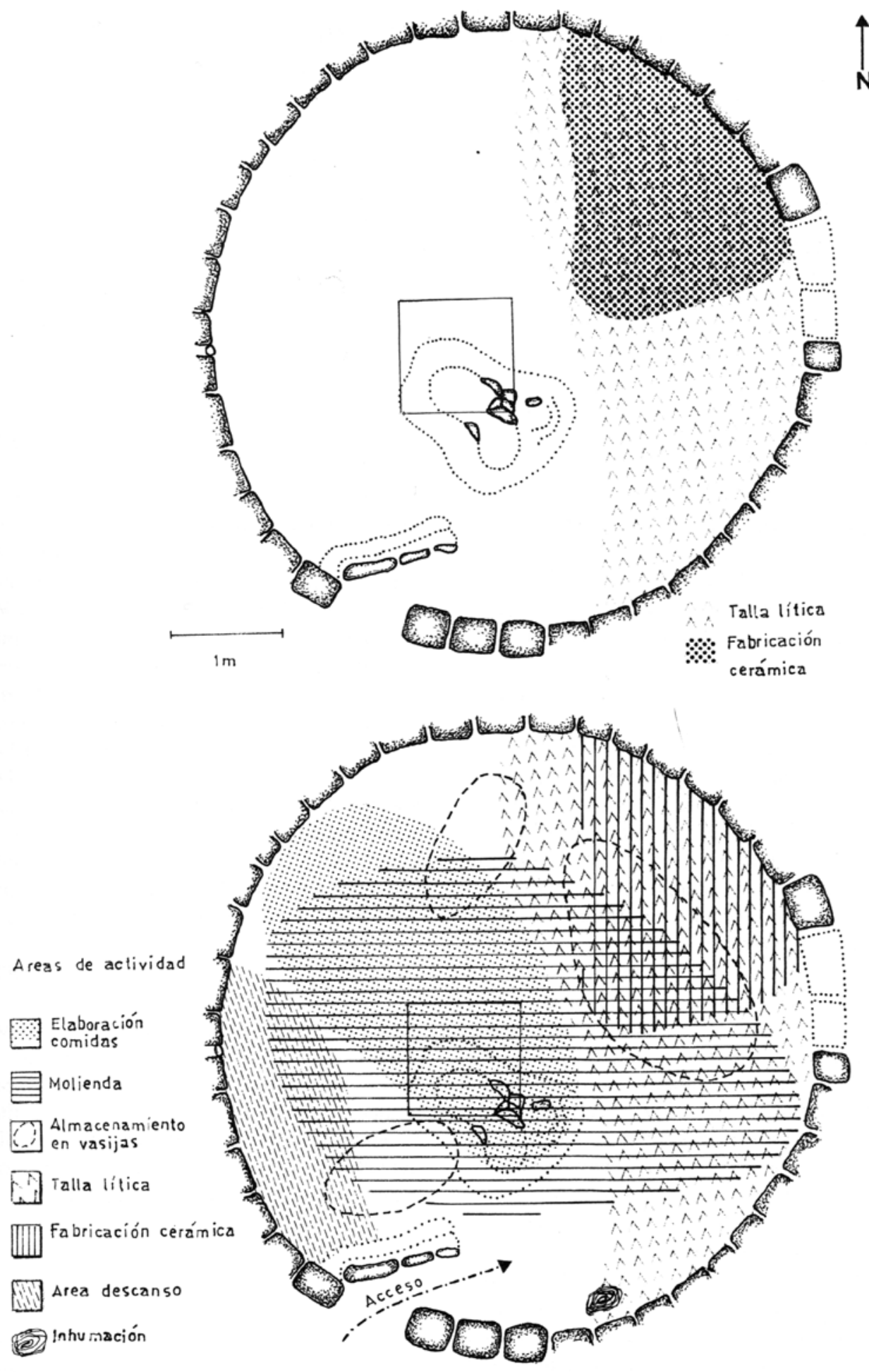

Figura 5. Areas de talla lítica y fabricación cerámica. Areas de actividad en el interior del recinto 1. 
Su función, indudablemente de índole ritual, sólo podría ser correctamente analizada en el caso de excavarse otras viviendas en el poblado ( $\mathrm{Tu}-1)$ y en tal caso verificar si es recurrente el entierro de párvulos o nonatos, si se trata de un hecho aislado en el contexto o si también se registran entierros de adultos o niños. En caso del recinto 1 se plantea la incógnita sobre el área de entierro para los demás ocupantes a lo largo del tiempo, porque la potencia del nivel fértil indicaría que la ocupación debió ser prolongada.

Talla lítica: Se circunscribe al sector oriental del recinto. En los sectores sureste y noreste se recuperaron la mayoría de las lascas de obsidiana, las tres puntas de proyectil y una raedera de la misma materia prima. Las lascas de obsidiana se concentran en los sectores S. 24 y S. 27.

Fabricación cerámica: La dispersión de los núcleos de arcilla rojiza cruda y pulidores se restringe al cuadrante noreste. Esto nos permitiría señalar este sector del recinto como espacio utilizado para las tareas de elaboración de cerámica. La mayor parte de estos elementos se encontró en las áreas cercanas a la pared.

Descanso: Esta área se identificó básicamente por la ausencia de hallazgos y por su posición dentro del recinto. Al elaborar los gráficos de dispersión se comprobó la recurrente baja frecuencia de materiales en los sectores S. 6 y S. 7. En particular la distribución del material óseo que está casi totalmente ausente en los sectores S. 3, S. 4, S. 6 y S. 7. Creemos que esta parte de la vivienda sirvió para dormir. Esta idea se ve apoyada, además, por la proximidad del fogón, la ausencia de desechos de comida y la situación protegida contra el viento y el frío, generada a partir de la ubicación del deflector que desvía el viento.

\section{Comentarios finales}

De lo expuesto se debe destacar la diversidad de tareas desarrolladas en el interior de la vivienda. Sin embargo, resulta difícil inferir la periodicidad con que se realizaron estas diversas tareas. Como aún no se ha excavado el entorno del recinto, no se puede establecer qué actividades también fueron desarrolladas en el exterior. La pequeña terraza pircada, sobre la cual se asienta el recinto 1 y otro recinto de iguales características, probablemente haya servido de patio.
Las condiciones climáticas imperantes en la zona, con una fuerte insolación y temperaturas tolerables durante el día, aun en pleno invierno, permiten el desarrollo de múltiples actividades a la intemperie. Mientras que durante el día, el interior de las habitaciones es oscuro y frío comparado con el exterior. Esto se registra entre los pobladores actuales de Casabindo que aprovechan la luminosidad y calor del sol para llevar a cabo la mayor parte de las tareas domésticas en los patios o al reparo de las paredes de las viviendas. Los espacios interiores se ocupan durante las horas más frías, desde que se hace poco agradable la permanencia en el exterior, en la tarde, y hasta que el sol nuevamente cobra fuerza en la mañana.

Ocasionalmente se ocupan las viviendas para guarecerse los días extremadamente ventosos del invierno y primavera o durante las tormentas de lluvia o granizo en el verano. Si proyectamos estas observaciones a la vivienda arqueológica y sus ocupantes, no resultaría extraño que algunas de las actividades registradas correspondan a vestigios de tareas desarrolladas tan sólo de manera esporádica dentro de la habitación. Las únicas actividades que podríamos plantear como diarias en el interior son: el descanso, el almacenamiento y el uso del fogón. La talla lítica, el hilado y el pulido de la cerámica debieron ocurrir muy espaciadamente. La elaboración y consumo de comidas y la molienda (en razón de la abundancia de artefactos vinculados a estas actividades) probablemente hayan sido algo más frecuentes. No podemos descontar la existencia de un fogón exterior como ocurre en la mayor parte de las viviendas rurales en la actualidad. Con referencia a la división sexual de las actividades domésticas registradas, se desprende que la única tarea de incumbencia exclusivamente masculina desarrollada en el interior corresponde a la talla lítica. Las demás tareas se hallan integradas a la esfera femenina (elaboración de comidas, molienda, hilado y probablemente también la fabricación cerámica) o corresponderían a áreas compartidas como el descanso.

No puede dejar de extrañarnos el abandono de la vivienda con la gran mayoría de sus elementos muebles in situ. A esto debemos agregar que en el sondeo practicado en el recinto 0, en la lomada alta, aparentemente ocurría un fenómeno similar. La excavación de otros recintos nos dará la pauta si es una mera coincidencia entre los recintos 1 y 0 es un hecho recurrente en todo el sitio. 
Por último, queremos poner en evidencia que el estudio de los diferentes elementos recuperados aún no ha concluido. Se ha encarado un análisis más exhaustivo del material cerámico, óseo y lítico que seguramente aportará nuevos datos que darán otros detalles de cómo fue la vida de estos antiguos habitantes de la Puna de Jujuy.

\section{REFERENCIAS CITADAS}

BOMAN, E., 1908. Antiquités de la Región Andine de la Repúblique Argentine et du Desert d'Atacama. Imprimerie Nationale, París.

CASANOVA, E., 1938. Investigaciones arqueológicas en Sorcuyo Puna de Jujuy. Anales del Museo Argentino de Ciencias Naturales XXXIX.

KRAPOVICKAS, P., A. S. CASTRO, M. M. PEREZ y R. J. CROWDER, 1979. La instalación humana en Santa
Ana de Abralaite (sector oriental de la Puna). Relaciones NS XII.

SCHIFFER, M., 1983. Toward the identification of formation processes. American Antiquity 48 (4): 675-706.

WILK, R. y M. SCHIFFER, 1979. The archaeology of vacant lots, Arizona. American Antiquity 44: 53-536.

\section{ADENDA}

Se han obtenido tres fechados radiocarbónicos para el recinto 1 de Pueblo Viejo de Tucute, estos fechados indicarían una ocupación más tardía, alrededor del 1300 DC, para dicho recinto:

LP-500: 680 \pm 50 años fue calibrado y daría 1300 DC y a dos sigmas entre 1217 y 1401 DC.
LP-506: 910 \pm 60 años fue calibrado y daría 1160 DC y a dos sigmas entre 1013 y 1275 DC.

LP-599: 670 \pm 60 años, este último fechado, realizado sobre colágeno de huesos de camélido, fue calibrado a dos sigmas dando entre 1218y 1402 DC. 